\title{
PUNISHMENT MENURUT PEMIKIRAN IBNU SHAHNUN DALAM PENDIDIKAN MODERN
}

\author{
Hamidatun Nihayah ${ }^{1}$ \\ M. Romadlon Habibullah ${ }^{2}$ \\ IAI Sunan Giri Bojonegoro \\ nehabhasya_bhasya@yahoo.com
}

\begin{abstract}
Abstrak
Pendidikan adalah bagian dari proses untuk mencapai sebuah tujuan yang dicitacitakan, yaitu dengan menjadikan manusia sebagai makhluk yang berakhlak dan unggul dalam ilmu pengetahuan, Dalam proses usaha mencapai tujuan pendidikan ada beberapa metode pembelajaran yang diterapkan di pendidikan formal, non formal maupun informal diantaranya adalah reward dan punishment Punishment atau hukuman dalam pendidikan adalah salah satu cara yang diberikan bagi siapa yang melanggar dan harus mengandung makna edukatif. Dengan harapan adanya punishment yang diberikan, anak didik tidak akan lagi melanggar aturan atau norma-norma yang ada serta mampu menjadikan mereka jera dan menjadi lebih baik. Menurut Ibnu Sahnun punishment atau hukuman yang diberikan atau diterapkan oleh pendidik kepada anak didik harus sesuai porsi dan syarat ketentuannya yang bernilai positif dan bertujuan mendidik. Bahkan menegaskan dengan sangat merupakan kesalahan besar apabila pendidik dalam memberikan hukuman didasarkan karena amarah atau kemarahan. Sehingga yang timbul adalah bukan lagi rasa kasih sayang namun sebaliknya
\end{abstract}

Kata kunci: pendidikan, punishment, Ibn Shanun.

\section{Abstract}

Education is part of the process to achieve a goal that is aspired to, namely by making people as beings who have morality and excellence in science. In the process of achieving educational goals there are several learning methods applied in formal, nonformal and informal education including reward and punishment Punishment or punishment in education is one of the ways given to those who violate and must contain educational meaning. With the hope that punishment will be given, students will no longer violate existing rules or norms and be able to make them deter and become better. According to Ibnu Sahnun punishment or punishment given or applied by educators to students must be in accordance with the portion and the terms of the provisions that are positive and educational in purpose. Even asserting very strongly is a big mistake if educators in giving a sentence are based on anger or anger. So what arises is not compassion, but vice versa.

Keywords: education, punishment, Ibn Shanun. 


\section{PENDAHULUAN}

Seiring dengan perkembangan peradaban manusia yang bergerak menuju lebih baik serta peradaban gemilang manusia modern, perkembangan pendidikan terus terjadi. Hanya melalui proses pendidikan yang baik pula, pencapaian peradaban gemilang bisa dilakukan. Proses pendidikan telah berlangsung mulai adanya Adam dan Hawa. Adam secara mandiri dididik langsung oleh Tuhan dengan diajarkan kepadanya beberapa nama benda sampai Adam menjadi makhluk yang unggul karena ilmu pengetahuannya. ${ }^{1}$ Perjalanan itu terus berlangsung hingga manusia semakin berkembang dalam segala hal, baik pengetahuan tentang diri sendiri sebagai makhluk biologis maupun pengetahuan sebagai makhluk pemimpin di muka bumi.

Ada dua tugas utama manusia yang harus dimiliki yaitu sebagai hamba Allah serta pemimpin di muka bumi. Balasan dan hukuman muncul bersamaan dengan penciptaan manusia itu sendiri.Pada zaman modern sekarang ini proses pendidikan berjalan sesuai dengan kebutuhan dan budaya setiap wilayah. Pelaksanaan pendidikan adalah bagian dari proses untuk mencapai sebuah tujuan yang dicita-citakan, yaitu dengan menjadikan manusia sebagai makhluk yang berakhlak dan unggul dalam ilmu pengetahuan. Pada proses pelaksanaan pendidikan ada metode pembelajaran sebagai bentuk upaya mewujudkan atau mencapai sebuah tujuan pendidikan yang telah dirumuskan dalam visi misi. Potensi pendidikan diharapkan supaya pelaksanaan pendidikan bisa berjalan dengan lancar dan capaian pendidikan bisa terwujud dengan baik. Budaya yang berkembang baik di Timur maupun di Barat, semuanya memiliki pola dan metode yang berbeda dalam mencapai tujuan pendidikan.

Tujuan pendidikan menurut Francois Rabelais (1483-1553) adalah pembentukan manusia yang lengkap dan cakap. Sedangkan menurut John Milton (inggris, 1608-1674) tujuan pendidikan adalah persiapan untuk kehidupan sebenarnya di dunia nyata ini. Sedangkan tujuan pendidikan Islam ini tidak jauh berbeda dengan yang dikemukakan para ahli. Menurut Ahmadi, tujuan pendidikan Islam adalah sejalan dengan pendidikan hidup manusia dan peranannya sebagai makhluk Allah SWT yaitu semata-mata hanya beribadah kepada-Nya

\footnotetext{
${ }^{1}$ Maman Fathurrohman. Al Qur`an dan Pengajaranyanya.Bandung: Pustaka Madani 2011. Hlm. 2.
} 
Firman Allah SWT. Dalam al Qur'an surat adz-dzariyat ayat 56:

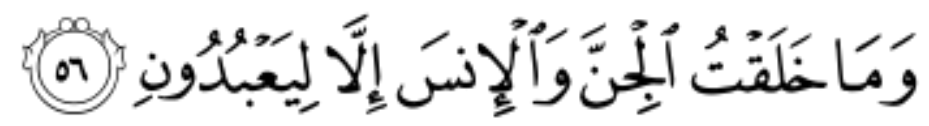

Terjemahnya:

Dan tidaklah aku menciptakan jin dan manusia melainkan supaya mereka menyembahku (QS. Adz-Dzariyat : 56) ${ }^{2}$.

Yusuf Amir Faisal merinci tujuan pendidikan Islam sebagai berikut :

a. Membentuk manusia muslim dapat melaksanakan ibadah mahdlah

b. Membentuk manusia muslim dapat juga melaksanakn ibadah muamalah dalam kedudukannya sebagai orang per orang atau sebagai anggota masyarakat dalam lingkungan tertentu.

c. Membentuk warga negara yang bertanggungjawab pada Allah SWT sebagai penciptaNya.

d. Membentuk dan mengembangkan tenaga professional yang siap dan terampil atau tenaga setengah terampil untuk memungkinkan memasuki masyarakat.

e. Mengembangkan tenaga ahli dibidang ilmu agama dan ilmu -ilmu Islam yang lainnya ${ }^{3}$.

Berdasarkan penjelasan dan rincian tentang tujuan pendidikan diatas maka dapat diambil kesimpulan bahwa tujuan pendidikan Islam adalah sebagai berikut :

a. Menyiapkan dan membiasakan anak dengan ajaran Islam sejak kecil agar menjadi hamba Allah SWT yang beriman.

b. Membentuk anak muslim dengan perawatan, bimbingan, asuhan, dan pendidikan pra natal sehingga dalam dirinya tertanan kuat nilai-nilai keislaman yang sesuai fitrahnya

c. Mengembangkan potensi, bakat dan kecerdasan anak sehingga mereka dapat merealisasikan dirinya sebagai pribadi muslim.

d. Memperluas pandang hidup dan wawasan keilmuan bagi anak sebagai makhluk individu dan sosial.

Barat dikenal modern dan secara kognitif bisa teruji, sehingga pendekatan yang diterapkan adalah dengan kajian empiris logis. Sedangkan budaya Timur dikenal dengan kearifan dan spiritualitas tinggi, oleh karenanya pendekatan yang dilakukan cenderung logis akhlaki. Tidak ada dikotomi ilmu dalam pendidikan, karena setiap orang berhak mengetahui segala ilmu sebagai modal mempertahankan hidup, pengembangan diri, maupun mengelola lingkungannya sebagai makhluk sosial.Dalam proses usaha mencapai

\footnotetext{
${ }^{2}$ Departemen Agama RI, op. cit., Jilid 9, 485.

${ }^{3}$ Yusuf Amir Faisal, Reorientasi pendidikan Islam, Jakarta : Gema Insani Press, 1995, 96.
} 
tujuan pendidikan ada beberapa metode pembelajaran yang diterapkan di pendidikan formal, non formal maupun informal diantaranya adalah reward and punishment.

Hukuman atau yang disebut denganpunishment tidak selalu diperlukan. Abdullah Nasih Ulwan mengatakan bahwa untuk membuat anak didik jera, pendidik harus berlaku bijaksana dalam memilih dan menggunakan metode yang paling tepat. ${ }^{4}$ Ada dari mereka dengan teladan dan nasehat saja sudah cukup, sehingga tidak membutuhkan hukuman(punishment). Tetapi, ada juga mereka yang ketika melakukan kesalahan perlu ditegasi atau diberikan hukuman(punishment). ${ }^{5}$

Abdul Mujib dan Jusuf Mudzakkir memaknai hukuman (punishment) sebagai salah satu cara yang diberikan bagi siapa yang melanggar dan harus mengandung makna edukatif. ${ }^{6}$ Misalnya, siapa yang terlambat masuk sekolah diberi tugas membersihkan lingkungan sekolah. Apabila tugas awal tidak diindahkan, maka semisal hukuman pukulan baru bisa diterapkan. Hukuman tersebut agartidak membahayakan saraf otak peserta didik, serta menjadikan efek negatif yang berlebihan maka dapatditerapkan bila anak didik telah sampai usia 10 tahun,. Sebagaimana sabda Nabi Muhammad Saw yang artinya

"Dari Amr bin Syu'aib ayahnya dari kakeknya bahwa Rasulullah Saw pernah berkata suruhlah anak-anakmu melakukan shalat sejak usia tujuh tahun dan Pukullah jika tidak mau sholat di usia sepuluh tahun, serta pisahkan tempat tidur mereka." (HR. Dawud) ${ }^{7}$

Pandangan setiap orang terkait punishment pasti berbeda. Dalam hal ini penulis, akan memaparkan pemikiran seorang tokoh pendidikan islam yang sangat berpengaruh dalam dunia pendidikan, beliau ibnu sahnun. Ibnu sahnun menyampaikan bahwa dalam punishment pelaksanaannya harus dibatasi sesuai dengan pelanggaran atau kesalahan anak didik. Agar yang terjadi padaanak didik tidak sekedar rasa jera, namun ada nilai-nilai positif yang bisa diambilnya.

\section{PEMBAHASAN}

\section{Ibnu Sahnun Dan Pemikirannya}

Pendidikan dalam islam sangat diperhatikan. Demikian ini terbukti dalam al Qur'an dan hadith yang banyak sekali membahas mengenai konsep dan prinsip. Maka, layak banyak sekali ahli pendidikan yang lahir dari islam. Salah satunya adalah Ibnu Sahnun. Ibnu Sahnun memiliki nama lengkapAbu Abdullah Muhammad bin Abi Sa'id bin Habib bin Hisan ibnu Hilal bin Bakar bin Robiah al-Tunukhi. Beliau diberikan nama Orang tuanyaAbdu al-Salam, karena kejeniusan dan kecerdasannya beliau mendapat gelar Sahnun yang berarti Burung Elang (al-Tho-ir-Hadid al-Nadzor). Beliau lahir di Qairawan,

\footnotetext{
${ }^{4}$ Abdullah Nasih Ulwan, Pendidikan Anak dalam Islam, terj. Jamaludin Miri (Jakarta, 1994), hal. 333

Abu Dawud, Terjemahan Sunan Abu Dawud, terj. Bey Arifin dan A. Syinqithy Djamaluddin (Semarang, 1992), hal. 326

${ }^{5}$ Muhammad Quthb, Sistem Pendidikan Islam, terj. Salman Harun (Bandung, 1993), hal. 341

${ }^{6} \mathrm{http}: / /$ fertobhades.wordpress.com/2006/11/12/hkmn/

${ }^{7}$ Abdul Mujib, Jusuf Mudzakkir, Ilmu Pendidikan Islam (Jakarta: Kencana, 2006), hal. 206
} 
Tunisia, Afrika Utara (202-256 H/813-869 M) dan merupakan pemikir yang yang mempelopori pembaharuan pendidikan di zaman keemasan Islam. ${ }^{8}$ Serta mengembangkan madzhab Maliki di Qairuwan Afrika Utara.

Ibnu Sahnun salah satu peletak dasar pertama bidang pemikiran pendidikan Islam, khususnya pemikiran pendidikan yang bebas dan berdiri sendiri serta lepas dari pengaruh sastra dan mazhab-mazhab pemikiran filsafat, yang sebelumnya belum ada yang membahas tentang ilmu pendidikan secara rinci dan jelas.

Ibnu Sahnun mengemukakan pemikiran pendidikannya dengan menggali sumber ajaran Islam yang asli yaitu al-Qur'an dan hadits nabi. Pemikiran Ibnu Sahnun mengenai pendidikan banyak menyoroti tentang perilaku pendidik, dan yang paling diperhatikan adalah berkenaan dengan kompetensi pendidik itu sendiri. Selain tanggung jawabnya dalam mengajar, seorang pendidik dituntut memiliki kemampuan atau kapasitas keilmuan yang mumpuni.

Pendapat IbnSahnūn bahwa, anak-anak adalah amana tbagi orangtua. Oleh itu,pendidikandan pembinaan untuk anak-anaksangatlah penting. Dengan demikian supaya tercipta manusia yang cerdas, pandai, berakhlak karimah, kreatif dan tegar dalam menghadapi kehidupan serta mampu bersosialisasi dan beradaptasi dengan lingkungan dimana ia tinggal maka potensi dasar yang dimiliki oleh anak-anak perlu dibentuk dan dibina agar tumbuh dan berkembang semaksimal mungkin. ${ }^{9}$

\section{Pandangan ibnu sahnun terhadap punishment dalam pendidikan modern.}

Pendidikan dalam islam (arab) terdapat dua istilah yaitu kata rabb dengan bentuk masdarnya tarbiyah dan kata 'allama dengan bentuk masdarnya ta'lim. Kata tarbiyah sebagaimana dijelaskan oleh al-Raghib al-Ashfahany adalah sya'a al-syai halan fa halun ila haddi al-tamam; artinya mengembangkan atau menumbuhkan sesuatu setahap demi setahap sampai batas yang sempurna. Sedangkan kata ta'lim digunakan secara khusus untuk menunjukkan sesuatu yang dapat diulang dan diperbanyak sehingga menghasilkan bekas atau pengaruh pada diri seseorang ${ }^{10}$. Kata $r a b b$ dengan segala derivasinya tersebut dalam al Qur'an sebanyak $981 \mathrm{kali}^{11}$ dan kata 'allama sebanyak $854 \mathrm{kali}^{12}$. Kata rabb dalam al Qur'an digunakan untuk menunjukkan obyek yang bermacam-macam, baik fisik maupun non fisik. Dengan demikian, pendidikan oleh Allah swt. meliputi pemeliharaan seluruh makhluk-Nya. Adapun kata 'allama digunakan dalam berbagai konteks yang terkadang digunakan untuk menjelaskan bahwa Allah sebagai subyek yang mengajarkan kepada manusia berbagai hal. Sehingga terkesan bahwa kata ta'lim dalam al Qur'an

\footnotetext{
${ }^{8}$ Abdurahman Utsman Hijazi. Al-Madzhab al-Tarbawi 'inda IbnuSahnun.( Beirut: Al-Maktab alAshriyah1995),. 62

9'Abd'AmirSyamsal-Dīn,al-Fikrat-Tarbawi 'IndaIbnSahnūnwaal-Qābisi,(Beirut:DarIqra,1985),40.

${ }^{10}$ Al-Raghib al-Ashfahany, Mu'jam Mufradat li Alfadz al-Qur'an, Bairut: Daār al-Fikr, t.t., h. 336.

${ }^{11}$ Muhammad Zaki Muhammad Khadr, Mu'jam Kalimat al-Qur'an al-Karim, Juz 12, 2005, h. 3.

${ }^{12}$ Ibid., Juz 20, h. 12.
} 
menunjukkan adanya sesuatu berupa pengetahuan yang diberikan kepada seseorang. Jadi, sifatnya intelektual.

Mengenai pemakaian kata tersebut dalam hubungannya dengan pendidikan terjadi perbedaan pendapat di kalangan para ahli. Menurut Abdurrahman al-Nahlawi dalam Ahmad Tafsir, bahwa kata tarbiyah lebih tepat digunakan untuk makna pendidikan. Menurutnya, kata Tarbiyah' berasal dari tiga kata, yaitu: pertama, dari kata raba-yarbu yang berarti bertambah atau tumbuh, karena pendidikan mengandung misi untuk menambah bekal pengetahuan kepada anak dan menumbuhkan potensi yang dimilikinya. Kedua, dari kata rabiya- yarba' yang berarti menjadi besar, karena pendidikan juga mengandung misi untuk membesarkan jiwa dan memperluas wawasan seseorang. Ketiga, dari kata rabba-yarubbu' yang berarti memperbaiki, menguasai urusan, menuntun, menjaga dan memelihara ${ }^{13}$.

Lain halnya dengan Abdul Fattah Jalal, beliau memaparkan bahwa kata ta'lim lebih komprehensif untuk mewakili istilah pendidikan karena kata tersebut berhubungan dengan tiga aspek. Pertama, menyangkut aspek pemberian bekal pengetahuan, pemahaman, pengertian, tanggung jawab, dan penanaman amanah, hingga penyucian atau pembersihan manusia dari segala kotoran dan menjadikan diri manusia berada dalam kondisi yang memungkinkan untuk menerima al hikmah serta mempelajari apa yang bermanfaat baginya dan yang tidak diketahuinya. Kedua, menyangkut aspek pengetahuan dan keterampilan yang dibutuhkan seseorang dalam hidup serta pedoman perilaku yang baik. Ketiga, merupakan proses yang terus menerus diusahakan semenjak dilahirkan, sebab menusia dilahirkan tidak mengetahui apa-apa, tetapi dia dibekali dengan berbagai potensi yang mempersiapkannya untuk meraih dan memahami ilmu pengetahuan serta memanfaatkanya dalam kehidupan ${ }^{14}$.

Pendidikan adalah bagian dari proses untuk mencapai sebuah tujuan yang dicitacitakan, yaitu dengan menjadikan manusia sebagai makhluk yang berakhlak dan unggul dalam ilmu pengetahuan, Dalam proses usaha mencapai tujuan pendidikan ada beberapa metode pembelajaran yang diterapkan di pendidikan formal, non formal maupun informal diantaranya adalah reward dan punishment.

Punishment atau hukuman sebagai alat pendidikan sebenarnya tidak dapat lepas dari sistem kemasyarakatan dan ketatanegaraan yang berlaku. Sistem dan ketatanegaraan yang dimaksud bagi masyarakat adalah peraturan atau adat istiadat. Bukan hal yang asing jika punishment atau hukuman diterapkan dalam hal pengajaran.

Hukuman merupakan masalah etis yang menyangkut hal jelek dan baik.Hukuman dalam proses pendidikan dapat didefinisikan sebagai penderitaan yang diberikan dengan sengaja oleh orang tua, guru dan lainnya setelah terjadi suatu pelanggaran, kejahatan atau kesalahan pada setiap anak didik". Ibnu Sahnun ketika membahas terkait pelaksanaan

${ }^{13}$ Ahmad Tafsir, Ilmu Pendidikan dalam Perspektif Islam, Bandung: Rosdakarya, 2010, h. 29.

14. Abdul Fattah Jalal, Min al-Usuli al-Tarbawiyah fi al-Islam, Mesir: Darul Kutub Misriyah. 1977, 32. 
hukuman sebagai alat paedagogis, menyatakan bahwa pelaksanaannya harus dibatasi sesuai dengan pelanggaran atau kesalahan anak didik. Dalam hal ini Ibnu Sahnun nampaknya menyadari betul terhadap dampak-dampak psikologis yang muncul dari hukuman terhadap perkembangan jiwa anak.

Pemikiran ibnu sahnun terkait pemberian hukuman terhadap anak. Pada suatu saat Ibnu Sahnun duduk bersama Sa'ad seorang anak perempuan Sa'ad datang dan menangis, dan setelah diketahui penyebab tangisan tersebut karena ia telah dipukul oleh gurunya, Ibnu Sahnun kemudian berkata; "Ketahuilah demi Allah aku akan beritahukan hari ini bahwa Nabi SAW. Bersabda: "Bahwa sejahat-jahat umatku adalah mereka yang mengajar anak kecil dengan sedikit kasih sayangnya kepada anak yatim dan keras (pemarah) terhadap orang miskin." Pada dasarnya ulama tidak menghendaki punishment atau hukuman digunakan sebagai alat untuk mendidik dalam pemberian hukuman pada anak, kecuali jika terpaksa. Ibnu Sahnun menambahkan bahwa merupakan perbuatan buruk yang akan mendapatkan balasan di akhirat, apabila memberikan hukuman didasarkan atas kemarahan yang tidak disertai niat mendidik dan membawa manfaat.

Menurut Ibnu Sahnun seperti memukul dapat diberikan kepada anak didik,asalkan tidak dilakukan secara berlebihan dan bertujuan mendidik. Bahkan Ibnu Sahnun secara tegas menyatakan bahwa hukuman yang diperbolehkan harus dibatasi dalam penerapannya seperti pukulan tidak boleh diberikan lebih dari tiga kali kecuali atas izin orang tua dari si anak didik yang membolehkan untuk lebih dari itu. Itupun bisa diterapkan jika si anak terbukti telah menyakiti orang lain.

Menurut Ibnu Sahnun ada beberapa syarat dalam memberikan punishment atau hukuman.Syarat-syarat tersebut adalah sebagai berikut:

a. Hukuman diberikan dengan kasih sayang.

b. Tidak menghukum karena dasar marah.

c. Hukuman demi kebaikan anak.

d. Hukuman berupa pukulan tidak lebih dari tiga kali, kecuali atas izin orang tua anak

e. Hukuman berupa pukulan dengan alat yang tidak membahayakan.

f. Tidak menyakiti fisik anak.

Ibnu Sahnun sangat memahami terkait bahaya memberikan hukuman yang tidak terukur terhadap perkembangan jiwa anak. Oleh itu, menurut beliau ada beberapa hal dalam memberian hukuman fisik yang juga perlu diperhatikan. Yaitu antara lain:

a. Memperhatikan akhlak murid.

b. Menghormati hak asasi anak didik meskipun anak masih kecil.

c. Tidak sembarangan dalam memberikan hukuman.

Memberikan punishment atau hukuman berdasarkan analisis psikologis terdapat dampak negatif dan positif.

1. Dampak Negatif 
a. Hukuman yang sewenang-wenangnya dapat menimbulkan perasaan dendam kepada si terhukum.

b. Menjadikan sebabanak lebih pandai menyembunyikan pelanggaran.

c. Mengakibatkan si pelalanggar kehilangan perasaan bersalah, karena kesalahannya dianggap telah dibayar dengan hukuman yang telah diterimanya.

d. Hukuman yang terlalu sering dilakukan akan dapat menimbulkan rasa ketakutan terhadap si penghukum.

\section{Dampak Positif}

a. Perilaku si pelanggar akan bisa lebih baik.

b. Memperkuat kemauan si pelanggar untuk menjalankan kebaikan

Berdasarkan pemaparan diatas nampaknyapunishment atau hukuman memiliki pengaruh negatif yang lebih banyak daripada positifnya. Bahkan seorang psikologpun cenderung tidak dapat menerima hukuman fisik karena telah mengetahui akibat buruknya. Ada beberapa saran atau langkah yang dapat dilakukan untuk menghindari punishment atau hukuman. Antaranya:

1) menciptakan suasana yang bersahabat dan hangat dengan anak didik

2) Pilihlah hukuman ringan dan singkat yang secara fisik maupun psikologis tidak membahayakan anak namun bermutu

3) Yakin mampu mengendalikan diri ketika melakukan hukuman.

4) pembiasaan perilaku yang baik dan positif dalam rangka pengalihan hal-hal yang negatif

5) membuat pasangan yang terdiri dari penghukum potensial dengan tanda petunjuk seperti misalnya "jangan" dan "tidak".

\section{KESIMPULAN}

Pendidikan adalah bagian dari proses untuk mencapai sebuah tujuan yang dicitacitakan, yaitu dengan menjadikan manusia sebagai makhluk yang berakhlak dan unggul dalam ilmu pengetahuan, Dalam proses usaha mencapai tujuan pendidikan ada beberapa metode pembelajaran yang diterapkan di pendidikan formal, non formal maupun informal diantaranya adalah reward dan punishment.

Punishment atau hukuman sebagai alat pendidikan sebenarnya tidak dapat lepas dari sistem kemasyarakatan dan ketatanegaraan yang berlaku. Sistem dan ketatanegaraan yang dimaksud bagi masyarakat adalah peraturan atau adat istiadat. Bukan hal yang asing jika punishment atau hukuman diterapkan dalam hal pengajaran.

Punishment atau hukuman dalam pendidikan adalah salah satu cara yang diberikan bagi siapa yang melanggar dan harus mengandung makna edukatif. Dengan harapan adanya punishment yang diberikan, anak didik tidak akan lagi melanggar aturan atau norma-norma yang ada serta mampu menjadikan mereka jera dan menjadi lebih baik. 
Menurut Ibnu Sahnun punishment atau hukuman yang diberikan atau diterapkan oleh pendidik kepada anak didik harus sesuai porsi dan syarat ketentuannya yang bernilai positif dan bertujuan mendidik. Bahkan menegaskan dengan sangat merupakan kesalahan besar apabila pendidik dalam memberikan hukuman didasarkan karena amarah atau kemarahan. Sehingga yang timbul adalah bukan lagi rasa kasih sayang namun sebaliknya.

\section{DAFTAR PUSTAKA}

Abdurrahman, Drajat, Zakiyah, Ilmu Pendidikan Islam, Jakarta:Bumi Aksara,1996.

Anderson and Krathwohl. (2010). Kerangka Landasan untuk Pembelajaran, Pengajaran, dan Asesmen. Yogyakarta: Pustaka Pelajar.

Arends, Richard. (2012). Learning to Teach. New York: McGraw-Hill.

Arsyad, Ashar. (2006). Media Pembelajaran. Jakarta: Raja Grafindo Persada.

Arikunto, Suharsismi. 2010. Prosedur Penelitian Suatu Pendekatan Praktik. Jakarta: Rineka Cipta

Atinah, Sri. (2011). Strategi Pembelajaran di SD. Jakarta: Universitas Terbuka.

Balitbang Puskur, Pengembangan Pendidikan Budaya dan Karakter Bangsa,( Kementrian Pendidikan Nasional, 2010)

Budiningsih, Asri. (2012). Belajar dan Pembelajaran. Jakarta: Rineka Cipta.

Creswell, J. (2012). Reserch Design Qualitative, Quantitative and Mixed Methods Approach. Singapore: Asia Pacific Pte. Ltd

Dick, Walter. Lou Carey, James O. Carey. 2009.The Systematic Design of Instruction. Fifth edition.

Dimyati dan Mudjiono. (2002). Belajar dan Pembelajaran. Jakarta: Rineka Cipta.

Hidayat, Sholeh, Pengembangan Kurikulum Baru, Bandung: remaja Rosdakarya, 2013.

Dawud,Abu. Terjemahan Sunan Abu Dawud, terj. Bey Arifin dan A. Syinqithy Djamaluddin. Semarang: Pustaka

Fathurrohman, Maman. Al Qur`an dan Pengajaranyanya. 2011. Bandung: Pustaka Madani

Hijazi, Abdurahman Utsman. Al-Madzhab al-Tarbawi 'inda IbnuSahnun. 1995. Beirut: Al-Maktab al-Ashriyah 
Mujib, Abdul dan Mudzakkir,Jusuf. Ilmu Pendidikan Islam 2006, Jakarta: Kencana.

Nasih Ulwan, Abdullah. Pendidikan Anak dalam Islam, terj. 1994. Jamaludin Miri Jakarta : Lentera.

Quthb,Muhammad. Sistem Pendidikan Islam, terj. Salman Harun 1993. Bandung: Angkasa.

Syams al-Dīn, 'Abd 'Amir. al- Fikr at-Tarbawi 'Inda Ibn Sahnūn wa al-Qābisi, 1985 . Beirut: Dar Iqra.

Venbriyanto , dkk, Kamus Pendidikan, Jakarta: Grafindo, 1996. 